\title{
PHYSICAL CHARACTERIZATION OF IBUPROFEN-STEARIC ACID BINARY MIXTURE DUE TO COMPRESSION FORCE
}

\author{
Dwi Setyawan*, Dewi Isadiartuti, Sita Desti Betari, Diajeng Putri Paramita
}

\begin{abstract}
Dept of Pharmaceutics, Faculty of Pharmacy, Airlangga University, Darmawangsa Dalam, 60286 Surabaya-Indonesia
\end{abstract}

Submitted: 06-01-2016

Revised: $15-01-2016$

Accepted: 21-02-2016

*Corresponding author Dwi Setyawan

Email:

dwisetyawan-

90@ff.unair.ac.id

\begin{abstract}
Aim of this research is to determine physical characteristic of ibuprofen-stearic acid due to compression force. Binary mixture of ibuprofen-stearic acid with weight ratio of $4: 6,5: 5$, and $6: 4$ was compressed under various compression force using hydraulic press with $13 \mathrm{~mm}$ diameter flat punch. Identification of solid state interaction between these two components was performed by Hot Stage Microscopy (HSM). Physical characterization was studied using Differential Thermal Analysis (DTA), X-ray Powder Diffraction (XRPD), Scanning Electron Microscopy (SEM), and Fourier Transform Infrared (FT-IR) spectroscopy. According to hardness measurement, 4:6 weight ratio has the highest tensile strength on $170.6 \mathrm{~N} / \mathrm{cm}^{2}$ under $19.93 \mathrm{kN}$ compression force. Interaction identification by HSM showed single blank line that indicates eutectic formation. Thermal analysis of DTA also revealed eutectic formation upon compression which the endothermic peak of ratio of $4: 6$ has the lowest melting temperature of $53.2^{\circ} \mathrm{C}$. X-ray diffraction of three peaks generally showed that peak intensity decreases as compression force increases, but at particular point it begins to increase again. Sintering phenomenon at the surface of compressed tablet was observed from SEM analysis. FT-IR study confirms the formation of simple eutectic.
\end{abstract}

Key words: ibuprofen, stearic acid, binary mixture, compression force, physical characterization

\section{INTRODUCTION}

Tablet are the most widely used solid dosage form with several advantages in term of administration, formulation, and manufacturing (Yoshinari et al., 2003).Tablet quality depends on formulation and process during manufacturing. Tablet manufacturing process produces thermal and mechanical energy which possibly results in physical interaction amongst components used (Hosaka et al., 2005). During tablet compression, interaction can undergo between active substances, active substance with excipient, or between excipients. Crystal lattice arrangement followed by deformation or fracture can undergo during tablet compression (Bandyopadhyay et al., 2005).

Ibuprofen is one of antipyretic drugs extensively produced in tablet dosage form. Ibuprofen is a non-steroidal anti-inflammatory drug (NSAID) derivative of propionic acid with a melting point of $77^{\circ} \mathrm{C}$ (Ali et al., 2010). Stearic acid is a tablet lubricant with melting point of $57.23^{\circ} \mathrm{C}$ (Wang et al., 2010). Eutectic is known to be formed on ibuprofen-stearic acid binary mixture that is seen on phase diagram studied by Differential Scanning Calorimetric (DSC) (Lerdkanchanaporn et al., 2001).

Eutectic is a mixture of one component on another. Eutectic can be formed unintended during manufacturing process, e.g. wet granulation and compression (Bi et al., 2003). Compression force is known to lead to the change on the properties of drug substance and excipients such as particle size, specific surface area, crystallinity, polymorphism, crystal habit; lead to sintering and eutectic interaction (Yoshinari et al., 2003; Setyawan et al., 2011; Bi et al., 2003). Compression force drives eutectic formation by intimate contact facilitation and decrease of thermal contact resistance that reduce separation and facilitate heat transfers. Unintentional eutectic formation on tablet dosage forms have been reported to cause unwanted changes of characteristics of tablets such as sticking, unpredictable hardness, and instability (Bi et al., 2003). Zalac et al. (1998) 
reported that wet granulated tablet formulation containing eutectic compounds of paracetamol and propyphenazone has disadvantage properties that the tablet unacceptably softened after storage at $40^{\circ} \mathrm{C}$ and $75 \%$ relative humidity for one month, although it was still stabile chemically.

On knowing thermally-induced eutectic formation between ibuprofen and stearic acid, this research was conducted to identify effect of compression force upon binary mixture of the eutectic compounds and determine its physical characteristics.

\section{MATERIAL AND METHODS}

Ibuprofen was purchased from Shasun Chemicals and Drugs Ltd., India, batch no. IBU0603674. Stearic acid was purchased from Hense Chemicals Manufacture Ltd., China.

Binary mixture of ibuprofen and stearic acid was prepared with weight ratio of 4:6, 5:5, and 6:4. Eutectic samples were obtained by compression using a $13 \mathrm{~mm}$ flat punch hydraulic press on compression forces of $4.9,9.9,19.9,24.9$, and $28.9 \mathrm{kN}$.

\section{Hot stage microscopy study}

Hot stage microscopy was conducted using polarizing microscope equipped with hot stage. The observation was made by first melting a small amount of the higher melting component on microscope slide to occupy about half the area under cover slip. After the first component had cooled and solidified, the lower melting component stearic acid was placed at the edge of cover slip near the first component, then the sample was heated until the stearic acid melted completely and contacted with the first component. Once the sample cooled and solidified, the temperature was raised gradually during the observation.

\section{Mechanical properties}

Five hundred (500) $\mathrm{mg}$ of each pure component and binary mixture was compressed with different applied force for 10s. Compressed tablets were stored in desiccator for 2 days for elastic recovery. Thickness and diameter were measured for each tablet. Hardness of tablets was measured using Erweka hardness tester. Tensile strength $(\sigma)$ $\left(\mathrm{kgf} / \mathrm{cm}^{2}\right)$ was calculated using following equation (Wu et al., 2005).

$$
\sigma=2 \mathrm{~F} / \pi \mathrm{D} \mathrm{t}
$$

where, $\mathrm{F}=$ hardness $(\mathrm{kgf}), \mathrm{D}=$ tablet diameter $(\mathrm{cm})$, and $\mathrm{t}=$ thickness $(\mathrm{cm})$.

\section{Differential thermal a nalysis study}

Differential thermal analysis was performed on differential thermal analyser (Mettler Toledo FP 85, Switzerland). $\pm 5 \mathrm{mg}$ of each sample was heated in hermetically sealed aluminium pans with heating rate of $5^{\circ} \mathrm{C} / \mathrm{min}$ at temperature of $30-200^{\circ} \mathrm{C}$.

\section{X-ray powder diffraction study}

$\mathrm{X}$-ray powder diffraction patterns were obtained using an X-ray powder diffractometer (Phillips X'Pert, Netherland) with $\mathrm{CuK} \alpha$ radiation $(1.54 \AA)$, at $40 \mathrm{kV}$ and $30 \mathrm{~mA}$, passing through a nickel filter with a divergence slit $\left(0.25^{\circ} \mathrm{C}\right)$, antiscattering slit $\left(0.5^{\circ} \mathrm{C}\right)$, receiving slit $(0.15 \mathrm{~mm})$. Samples were scanned at rate of $2.4^{\circ} \mathrm{C} / \mathrm{min}$, over the $2 \theta$ range of $5-50^{\circ} \mathrm{C}$. Obtained diffractograms were analysed with Winplotr diffraction software.

\section{Scanning electron microscopy study}

Scanning electron-micrographs of tablet surface of compressed pure components and binary mixture were obtained using a Hitachi TM3000, Japan, with magnifications of 1000.

\section{Fourier transform infrared spectroscopy study}

FTIR spectra were measured using a Shimadzu 8400s FTIR spectrometer, Japan. Samples were dispersed in potassium bromide powder and compressed on $29.4 \mathrm{kN}$ forces by a hydraulic press to form transparent disc. Each sample's spectrum was recorded from 4000 to $450 \mathrm{~cm}^{-1}$.

\section{RESULTS AND DISCUSSION Hot stage microscopy study}

Hot stage microscopy is a simple technique to identify the type of physical interaction between two compounds by observation of phase behaviour upon heating. Crystalline phases direct the polarized light so that it will be seen under polarizing microscope with certain colour and intensity in regard to fragment orientation, thickness, and the absorbed polarized light by crystalline 
fragment. In other hand, liquid phases allow the light to pass through unchanged so no light reaches microscope (Davis et al., 2004; Zaini et al., 2011). Thus, it will be recognized as a black line or region as crystalline phases melt to form liquid phases (Davis et al., 2004).

Phase behaviour of ibuprofen and stearic acid is shown in Figure 1. Re-crystallized phase of ibuprofen is marked by number 1, recrystallized phase of stearic acid is by number 2 , and contact area is by number 3. It's clearly seen that contact area of two components is melted first than the pure component as temperature raised (Figure $1 \mathrm{~B}$ ), leaving single blank line between crystalline phases.

In the occurrence of eutectic interaction, the contact area of two compounds exhibits different melting behaviour with lower melting point compared to the pure compounds. If a simple eutectic is formed, single blank line would be observed in the contact area when the temperature is raised (Davis et al., 2004). Result shown in Figure 1 indicates formation of eutectic, the simple one, between ibuprofen and stearic acid and confirms result of previously conducted experiment (Lerdkanchanaporn et al., 2001).

Simple eutectic (conglomerate mixture) has reported to be formed on hot stage microscopy study of trimethropimnicotinamide conducted by Zaini et al. (2011). It was observed in the contact area new habit crystal distinguished from habit of pure compounds and it melted first as the sample was reheated, followed respectively by nicotinamide and trimethropim crystalline phase (Zaini et al., 2011).

\section{Mechanical Properties}

Mechanical properties from the elastic modulus curve are shown in figure 2 . Both pure compounds exhibit highest tensile strength at $19.9 \mathrm{kN}$ compression force. The binary mixtures follow the same pattern with different tensile strength values and the highest one is binary mixture of 4:6 weight ratio. Since ibuprofen and stearic acid are hydrophobic substances due to long fatty acid chain, its binary mixture may have higher compactibility that results in uncontrolled tablet hardness (Bi et al., 2002; Bergman et al., 1965; Adeyeye and Brittain, 2008). According to figure 2, tensile strength value tends to increase in the binary mixture compared to the pure compounds. This is probably because the binary mixture forms eutectic (will be discussed further in thermal analysis) which has more plastic properties (Bi et al., 2003). So, it can be concluded that compressed 4:6 weight ratio binary mixture is the most plastic characteristic.

The same result is also obtained with binary mixtures of acetaminophencaffeine anhydrous and acetaminophenprophylphenazone investigated by $\mathrm{Bi}$ et al. (2003). Each binary mixture is known to form eutectic, in different $\%$ formed, under compression, and the tablet properties study resulted in eutectic has no negative effect of eutectic on tablet hardness.

Based on the elastic modulus curve, binary mixture of 4:6 weight ratio and its compressed tablet under $19.9 \mathrm{kN}$ force is chosen for further physical characterization.

\section{Differential Thermal Analysis}

DTA analysis showed melting point of compressed ibuprofen and compressed stearic acid at $19.9 \mathrm{kN}$ is $78.7^{\circ} \mathrm{C}$ and $59.4^{\circ} \mathrm{C}$ respectively, and enthalpy energy of $95.3 \mathrm{~J} / \mathrm{g}$ and $116 \mathrm{~J} / \mathrm{g}$ respectively (Figure 3). Compressed 4:6 weight ratio binary mixture of ibuprofenstearic acid gives single different endothermic peak compared to the pure components with lower melting point at $54.1^{\circ} \mathrm{C}$. It confirms eutectic formation of ibuprofen-stearic acid even under compression. Melting point depression and high modulus elasticity curve of the compressed binary mixture shows physical interaction of these two components that may cause crystallinity change in its mixture (Zaini et al., 2011; Putra et al., 2012).

\section{X-Ray Powder Diffraction Study}

$\mathrm{X}$-ray diffractions of binary mixture of 4:6 weight ratio under various compression forces are shown in figure 4 . Three specific peaks at $2 \theta=6.4^{\circ}, 16.8^{\circ}$ and $23.8^{\circ}$ is used for calculation of peak intensity. Figure 5 shows that the intensity value decreases with the increasing of compression force. However,the intensity increases generally at high compression force over than $14.9 \mathrm{kN}$. Intensity represents strength of lattice preferred orientation. 

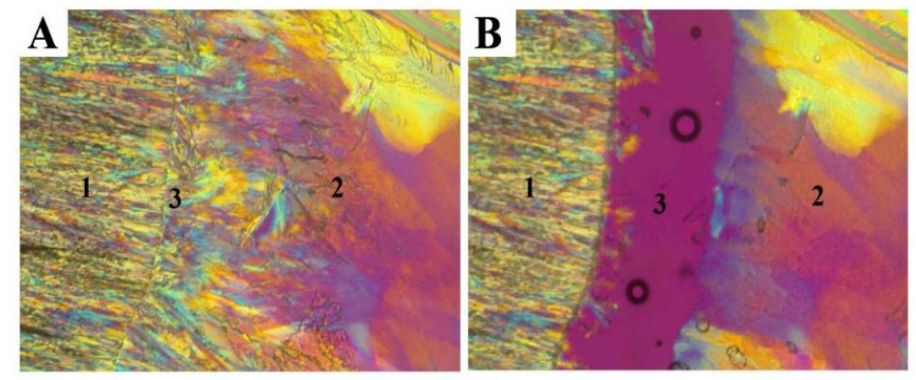

Figure 1. Observation of mixed fusion behaviour of ibuprofen and stearic acid, A. Formation of contact area, and B. First melting of contact area, $(1=$ ibuprofen, $2=$ stearic acid and $3=$ contact area)

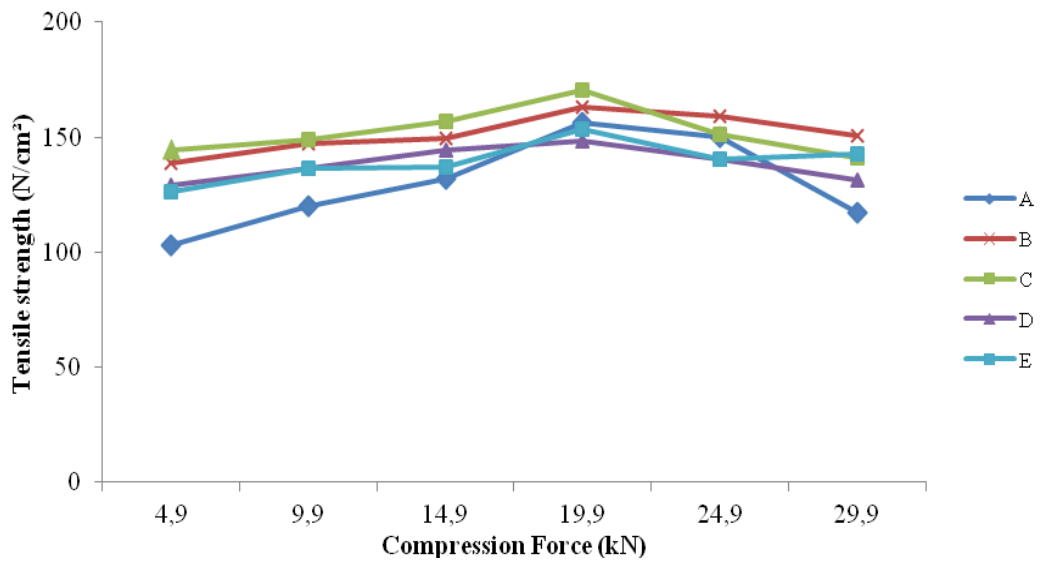

Figure 2. Elastic modulus of A. Ibuprofen, B. Stearic acid, C. Ibuprofen-stearic acid weight ratio of 4:6, D. 5:5, and E. 6:4.

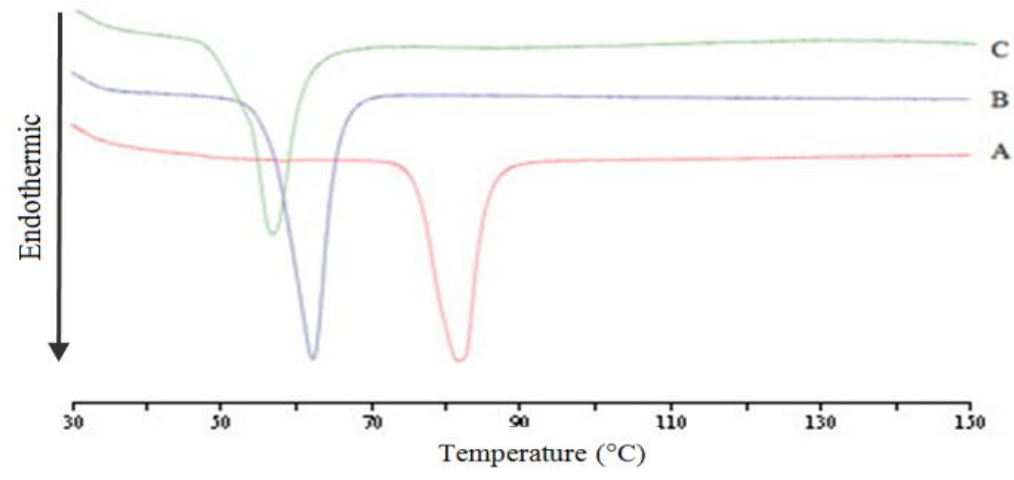

Figure 3. DTA thermograms of A. Ibuprofen, B. Stearic acid, C. Compressed binary mixture of ibuprofen-stearic acid of 4:6 weight ratio at $19.9 \mathrm{kN}$.

It can be predicted that crystallite breaks after compression at low force $(4.9 \mathrm{kN})$, but the crystallite's breakage fills the void space between adjacent crystallites at high compression force $(19.9 \mathrm{kN})$, result in increasing lattice order (Rippi et al., 2000).

\section{Scanning electron microscopy study}

SEM was used to evaluate the surface morphology of compressed pure components and its binary mixture of 4:6 weight ratio. It was observed that bar-shaped crystal habit of ibuprofen still remains on compressed tablet 


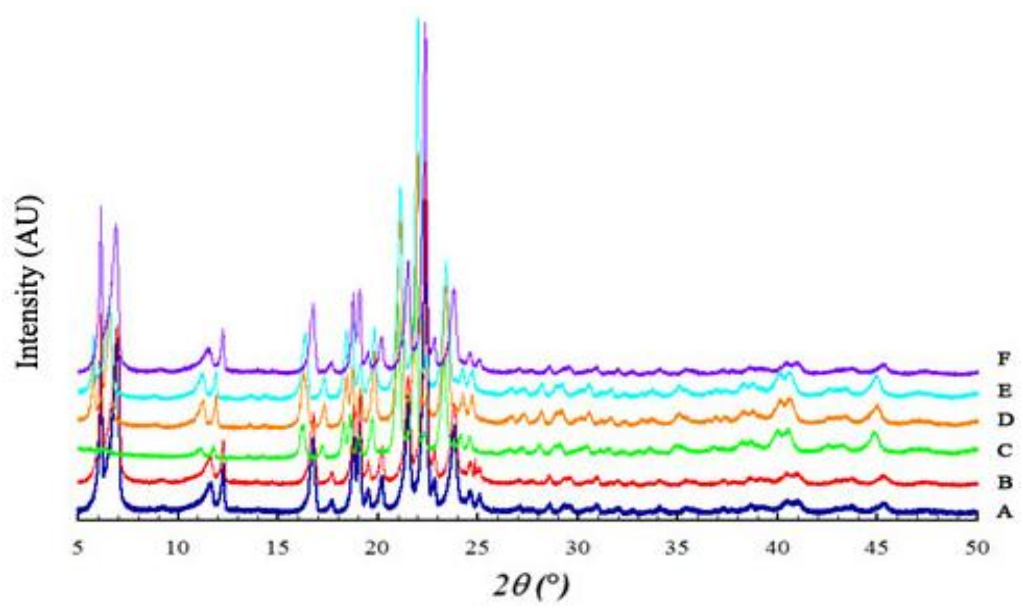

Figure 4. X-ray diffractograms of 4:6 weight ratio ibuprofen-stearic acid binary mixture under compression force of A. $4.9 \mathrm{kN}$, B. $9.9 \mathrm{kN}$, C. $14.9 \mathrm{kN}$, D. $19.9 \mathrm{kN}$, E. $24.9 \mathrm{kN}$, and F. $29.9 \mathrm{kN}$.

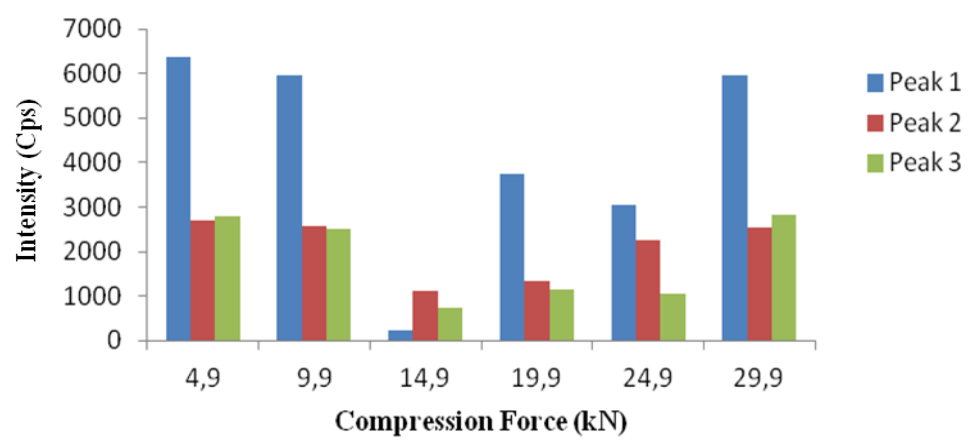

Figure 5. Intensity of three specific peaks of compressed 4:6 weight ratio ibuprofen-stearic acid binary mixture under different compression force.

(Figure 6C). However, sintering phenomenon was observed in compressed stearic acid as it losses surface border of the plate-shaped habit (Figure 6D). It was also observed on compressed binary mixture (Figure 6E).

Sintering phenomenon under compression is generally explained by impact of temperature increase due to interparticle friction during compression. The component with lower melting point melts and facilitates sintering at temperature above lower melting component by causing rearrangement of solid particle sliding over each other. After the heat and the pressure are removed, solidification occurs and results in solid bonds formation between particles in compressed tablet (Swarbrick and Boylan, 1996).
The effect of sintering on compact powder has known to cause microstructure changes as the sample of ibuprofen was compressed at force of $215 \mathrm{kgf} / \mathrm{cm}^{2}\left(21 \mathrm{kN} / \mathrm{m}^{2}\right)$ and heated at $70^{\circ} \mathrm{C}$ for $24 \mathrm{~h}$. Coalescence of deformed particles occurred on the surfaces of the compact within microscopic observation (Swarbrick and Boylan, 1996). Sintering was also reported for compressed erythromycin stearate at various compression forces (Setyawan et al., 2011). It was seen on scanning electron micrographs that particles of erythromycin stearate loss its surface boundary even at low force of $4.9 \mathrm{kN}$ and fuse with the adjacent at higher force. 

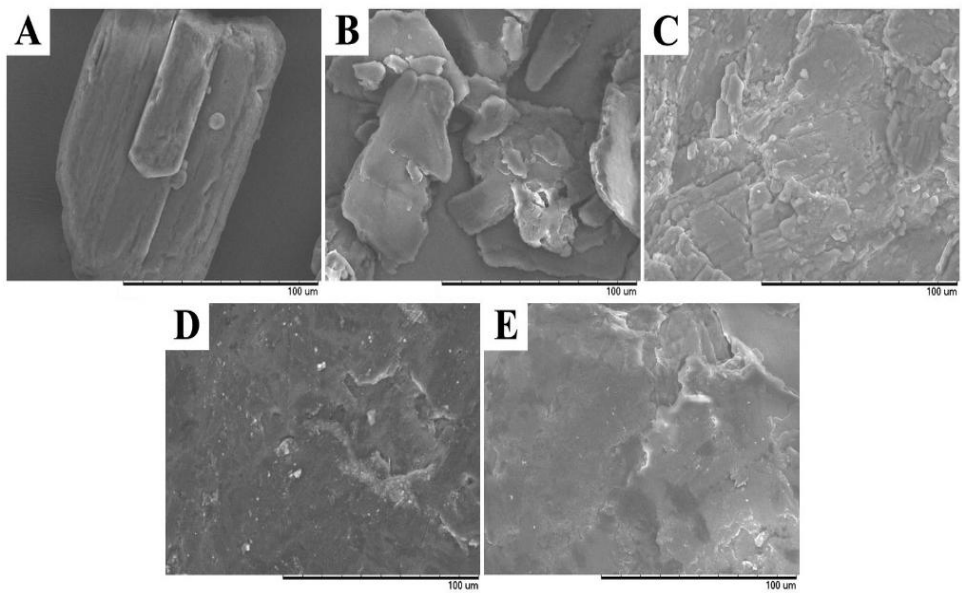

Figure 6. Scanning electron micrographs of A. Ibuprofen, B. Stearic acid, C. Compressed ibuprofen at $19.9 \mathrm{kN}, \mathrm{D}$. Compressed stearic acid at $19.9 \mathrm{kN}$, and E. Compressed 4:6 weight ratio binary mixture of ibuprofen-stearic at $19.9 \mathrm{kN}$.

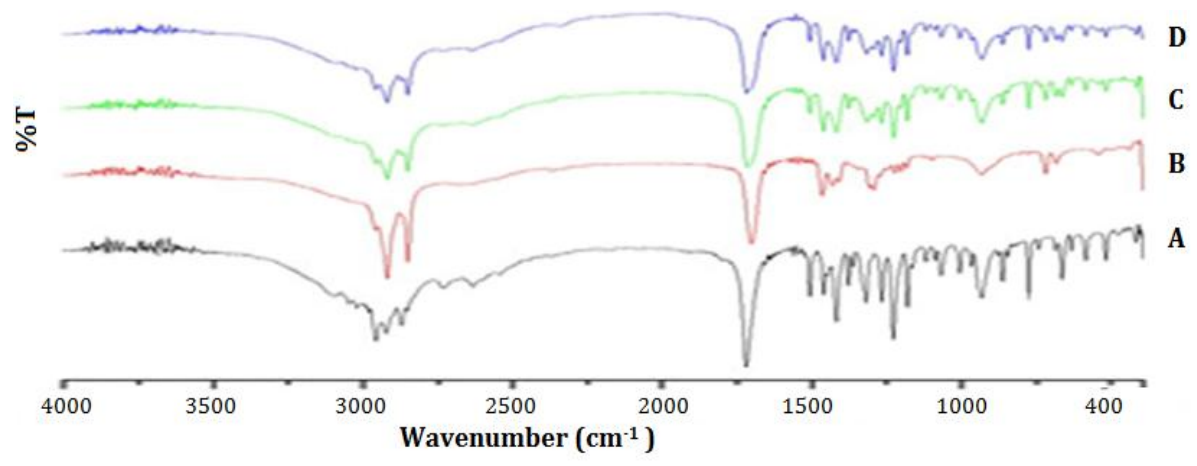

Figure 7. FT-IR spectra of A. Ibuprofen, B. Stearic acid, C. Binary mixture of 4:6 weight ratio, and D. Compressed binary mixture of 4:6 weight ratio at $19.9 \mathrm{kN}$

\section{Fourier transform infrared spectroscopy study}

Figure 7 shows FT-IR spectra of pure components and its binary mixture of 4:6 weight ratio. Ibuprofen gives sharp specific peak of $\mathrm{C}=\mathrm{O}$ group at $1720 \mathrm{~cm}^{-1}$ and broad peak at $\mathrm{OH}$ group's region. Stearic acid yields sharp peak at $1703 \mathrm{~cm}^{-1}$ for $\mathrm{C}=\mathrm{O}$ group and two sharp peaks at 2917 and $2848 \mathrm{~cm}^{-1}$. Compressed and uncompressed binary mixture depicts no significant difference of peak transmission as it's seen to be superimposed to each other. New hydrogen bond involving $\mathrm{OH}$ and $\mathrm{C}=\mathrm{O}$ group can be detected if change in intensity and peak take place (Putra et al., 2012). Thereupon, it can be concluded that upon compression ibuprofen and stearic acid binary mixture undergoes simple eutectic.

\section{CONCLUSION}

Physical interaction of eutectic formation between ibuprofen and stearic acid had been characterization. The physical interaction is formed under compression force, which is supported by mechanical properties and thermal analysis of the compressed binary mixture that shows higher compactibility than the pure components and new single endothermic peak at $54,1^{\circ} \mathrm{C}$, respectively. Physical interaction due to compression is also confirmed by increasing X-ray diffraction peak intensity at high compression $\mathrm{f}$ orce, sintering phenomenon, and not involving new hydrogen bonding based on FT-IR study. Due to eutectic interaction can occur by compression and gives different physical characteristics, it's essential to 
pay more attention on formula and technology involved in tablet manufacturing.

\section{ACKNOWLEDGEMENT}

The authors thanks to the Ministry of Research, Technology and Higher Education for providing Research Grant through of BOPTN Airlangga University.

\section{REFERENCES}

Adeyeye MJ., and Brittain HG., 2008, Chapter 4.1. Overview of Solid Dosage Form Preformulation Program in Preformulation in Solid Dosage Form Development, edited by Brittain H. G., Informa Health Care Inc., New York, USA : 347-355.

Ali W., Williams AC., and Rawlinson CF., 2010. Stochiometrically governed molecular interactions in drug: poloxamer solid dispersion. Int. J. Pharm. 391 : 162-8.

Bandyopadhyay R., Jon S., Gregory EA., Michael H., 2005. Application of powder $\mathrm{X}$-ray Diffraction in studying the compaction behavior of bulk pharmaceuticals powder. J.Pharm.Sci. 94: 25202530.

Bergman L., Bandeline F., 1965. Compatibility studies between carbamazepine and tablet excipients using thermal and nonthermal Methods. J.Pharm.S ci. 54:445.

Bi M., Sung JH., Kenneth RM., 2002. Mechanism of eutectic formation upon compaction and its effects on tablet properties. Therm.Act. 404: 213-226.

Davis RE., Lorimer KA., Wilkowski MA., Rivers JH., Wheeler KA., and Bowers J., 2004. Studies of phase relationships in cocrystal systems. ACA Trans.39: 41-61.

Hosaka S., Sato M., Ozawa Y., Hamada C., Takahashi Y., Kitamori N., 2005. Effect of compression on interaction between 1,4-dihydropyridine compounds and lactose Monohydrate. Chem.Pharm.Bull. 53(5): 503-507.

Lerdkanchanaporn S., Dollimore D., Evans S. J., 2001. Phase diagram for the mixtures of ibuprofen and stearic acid. Therm. Act. $367: 1-8$.

Putra OD., Nugrahani I., Ibrahim S., Uekusa H., 2012. Semi-crystalline and co-crystal of paracetamol Formation. JMS 17(2): 83-88.

Rippi M., Tanninen VP., Yliruusi J., 2000. Effect of compression force on crystal properties of erythromycin acitrate tablets. Eur J. Pharm. Biopharm. 50: 365371.

Setyawan D., Sumirtapura, YC., Soewandhi, SN., and Darjono Hadi Tj., 2011. Characterization of physical properties of binary system of erythromycin stearate-sodium starch glycolate by compression force effect. Indonesian.J.Phar:: 43-49.

Swarbrick J. and Boylan JC., 1996. Sintering in Pharmaceutics in Encyclopedia of Pharmaceutical Tecbnology Volume 14th 2nd Edition, edited by Li LC. and Li JH., Marcel Dekker, New York, USA, pp 87-101.

Wang J., Davidovich M., Desai D., Bu D., Hussain M., Morris M., 2010. Solid-state interactions of a drug substance and excipients and their impact on tablet dissolution: a thermal-mechanical facilitated process-induced transformation or PIT. J. Pharm. Sci. 99 (9): 3849-3862.

Wu C., Best SM., Bentham AC., Hancock BC., Bonfield W., 2005. A simple predictive model for the tensile strength of binary tablets. Eur. J. Pharm. Sci. 25:331-336.

Yoshinari T., Forbes TR., York P., Kawashima Y., 2003. The improved compaction properties of mannitol after a moisture induced polymorphic transition. Int. J. Pharm.258: 121-131.

Zaini E., Halim A., Soewandhi SN., Setyawan D. 2011. Solubility rate improvement of trimethoprim using co-crystallization method with nicotinamide. JFI 5(4):205212.

Zalac S., Khan MZI., Gabelica V., Tudja M., Mestrovic E. and Romih M., 1998. Paracetamol-propyphenazone interaction and formulation difficulties associated with eutectic formation in combination solid dosage forms. Chem. Pharm. Bull. 47(3): 302-307. 